\title{
Simplified spectrophotometric acid- base titrations to assess organic matter reactivity
}

\author{
MARAWIT TESFA ${ }^{1}$, REMI MARSAC ${ }^{2}$, ALINE DIA ${ }^{3}$ AND \\ FABRICE MAHE ${ }^{4}$ \\ ${ }^{1}$ CNRS-UMR 6118 Géosciences Rennes \\ ${ }^{2}$ Géosciences Rennes - UMR CNRS 6118 \\ ${ }^{3}$ Univ Rennes, CNRS, Géosciences Rennes, UMR 6118 \\ ${ }^{4}$ IRMAR, UFR Mathématiques Equipe d'analyse numérique \\ Presenting Author: marawit.tesfa@univ-rennes1.fr
}

In environmental issues, including soil quality and contamination studies, Natural Organic Matter (NOM) holds a crucial role because of its size, ubiquity and high reactivity. NOM's adsorption onto mineral surfaces and reactivity towards various contaminants and trace elements are mainly related to their acid-base groups such as, carboxylic and phenolic ones. To study these groups, different characterization and quantification methods have been developed. Acid-base potentiometric titration is the most reliable one but, is time-consuming and often impossible to apply to environmentally relevant NOM concentrations. Recent studies showed the great potential of spectrophotometric titrations in NOM analysis ${ }^{1,2}$. UV-vis spectra of a NOM solution are recorded for different values of $\mathrm{pH}$. The relative absorbance $(\Delta \mathrm{A}(\lambda, \mathrm{pH}))$ with respect to a reference $\mathrm{pH}$ (e.g. $\mathrm{pH} 3$ ) was shown to evolve according to:

$\Delta \mathrm{A}(\lambda, \mathrm{pH})=\mathrm{A}_{1}(\lambda) \times \mathrm{f}_{1}(\mathrm{pH})+\mathrm{A}_{2}(\lambda) \times \mathrm{f}_{2}(\mathrm{pH})$ eq. 1

Where $A_{1}(\lambda)$ and $A_{2}(\lambda)$ are specific absorbance of carboxylic and phenolic groups, respectively, $\mathrm{f}_{1}\left(\left[\mathrm{H}^{+}\right]\right)$and $\mathrm{f}_{2}\left(\left[\mathrm{H}^{+}\right]\right)$are functions of $\mathrm{pH}$. However, the proposed methods face some limitations. Firstly, data acquisition is time-consuming $(\sim 4 \mathrm{~h})$ and can hardly be automated. Secondly, the analysis of $\Delta \mathrm{A}(\lambda, \mathrm{pH})$ instead of the absorbance $\mathrm{A}(\lambda, \mathrm{pH})$, leads to larger analytical errors and a loss of spectroscopic information. Thirdly, eq. 1 is generally applied for a single wavelength, overlooking information in the rest of the spectra. Finally, absorbance data do not allow direct quantification of carboxylic and phenolic groups concentration, which requires potentiometric titration.

In this study, a method based on the use of $\mathrm{pH}$ buffer in acidbase titration speeded up to 4 times the sample preparation, and gave similar results to the published method. Equation 1 was modified to elaborate a MATLAB script allowing the use of $\mathrm{A}(\lambda, \mathrm{pH})$ and the estimation of functional groups' proportion, behavior and specific UV-vis spectrum. By analyzing NOM reactivity for seven IHSS standard samples, empirical equations are proposed for a direct estimation of carboxylic and phenolic groups concentrations.

The present development will help measuring NOM reactivity, hence providing constraints for the modeling of contaminants' fate in the environment.

[1] Janot et al., Environ. Sci. Technol. 2010, 44 (17), 6782 6788.

[2] Liu et al., Chemosphere 2020, 261, 128189. 